\title{
Study on the antioxidant capacity of Hibiscus rosa-sinensis decoction in vivo in Mus musculus var. albino
}

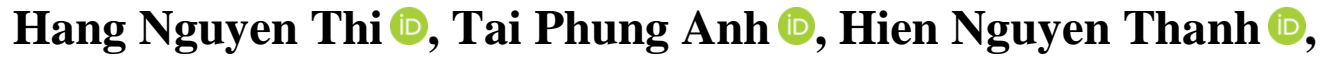

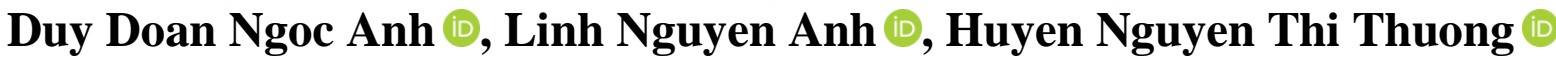 \\ Ho Chi Minh City University of Education, \\ 280 An Duong Vuong St., Ward 4, District 5, Ho Chi Minh City, Vietnam
}

Corresponding authors: Hang Nguyen Thi (hangnt@hcmue.edu.vn); Huyen Nguyen Thi Thuong (huyenntth@hcmue.edu.vn)

\begin{abstract}
Background: In humans, many diseases including cancer are associated with the accumulation of free radicals. Antioxidants can scavenge free radicals and minimize those impacts. Therefore, the antioxidants are used in cosmetic products, food supplements and medicine to modify the physiological functions. There are many cancer treatment options such as surgery, radiation therapy and chemotherapy and these methods bring lots of side efects to patients. Besides, Endoxan is a medicine commonly used to treat cancer, containing a compound called cyclophosphamide. However, using cyclophosphamide has many side effects, especially it elevates lipid peroxidation. According to the Oriental Medical, the flower, leaves and root of $\mathrm{Hi}$ biscus rosa-sinensis are commonly used to reduce the inflammation, furuncles, etc. The aim of the study: This study proved that Hibiscus rosa-sinensis has the antioxidant activity and the ability to recover liver functions when it was coordinated with cyclophosphamide in mice model. Materials and methods: Reducing power assay, DPPH free radical scavenging assay, and lipid peroxidation assay are utilised to identify the antioxidant activity of the Hibiscus rosa-sinensis flower decoction. Results: We have defined that the decoction of Hibiscus rosa-sinensis flower exhibits reducing power at $1 \%$ concentration which the optical density value is 1.51 , the $\mathrm{IC}_{50}$ value in DPPH free radical scavenging assay is $0.13 \pm 0.01 \%(\mathrm{p}<0.05)$ and at $1.71 \%$ concentration of the flower decoction the lipid peroxidation in the liver of the experimental group decreased 50\% compared to that of the control. In the mice model, the malonyl dialdehyde level in the liver of the mice continuously drinking at $1.71 \%$ concentration of the decoction in 1 day and 7 days was 2.3 times fewer than the control. Accordingly, the malonyl dialdehyde level in the liver of the mice drinking the decoction for 7 days was 1.93 times fewer than the 1-day trial under the same exper-
\end{abstract}


imental conditions. Conclusion: The decoction of Hibiscus rosa-sinensis has the ability to support the liver function in treating cancer.

Keywords: reducing power; DPPH free radical scavenging; malonyl dialdehyde Acknowledgements: The authors would like to thank for the Biology Faculty, HCMC University of Education to support the financy for this research. We are also thankful to MSc. Tam Nguyen Thi Thanh who positively assisted in completing this study.

For citation: Nguyen Thi H, Phung Anh T, Nguyen Thanh H, et al. Study on the antioxidant capacity of Hibiscus rosa-sinensis decoction in vivo in Mus musculus var. albino. Research Results in Biomedicine. 2021;7(2):149-155. DOI: 10.18413/26586533-2021-7-2-0-5

Introduction. Nowadays, there are many cancer treatment options such as surgery, radiation therapy and chemotherapy, especially chemotherapy is commonly used. However, this method brings lots of side efects to patients, for example causing immune response; badly affecting the liver and kidney function. Endoxan is a medicine commonly used to kill cancer cells containing a compound called cyclophosphamide. However, cyclophosphamide obstruct the hepatic vein; raise the liver enzymes for example alanine aminotransferase, aspartate aminotransferase, etc and cause acute liver failure, especially elevating lipid peroxidation. Scientific research indicates that cyclophosphamide has a toxic effect on the animal model. Accordingly, when cyclophosphamide is transported through the liver, it is converted into 4-hydroxycyclophosphamide and aldophosphamide with high alkylation, leading to the formation of cytotoxic agents, elevating lipid peroxidation in the liver [1]. Therefore, we propose a research model combining cyclophosphamide with a phytomedicine with good antioxidant capacity to inhibit lipid peroxidation, help recover liver function. According to Oriental Medicine, Hibiscus species are used to cool detoxify, treat inflammation, treat diabetes and so on. In 2016, Chi Nguyen Minh and colleagues showed that Hibiscus flower exhibited the highest antioxidant activity compared to its stems and leaves due to the DPPH free radical scavenging assay [2].

Therefore, the present study aims to investigate the ability of Hibiscus flower decoction to inhibit lipid peroxidation in the liver of the mice poisoned by cyclophosphamide. The results of the research provide scientific evidence for cancer treatment applications.

\section{Materials and methods.}

Decoction preparation. Hibiscus rosasinensis flowers were collected on Nguyen Dong Chi Street, District 7, Ho Chi Minh City, were identified by MSc. Nguyen Thi Thanh Tam (Department of Plant taxonomy, in HCMC University of Education). $10 \mathrm{~g}$ of the dried Hibiscus rosa-sinensis flowers was boiled with $350 \mathrm{~mL}$ of distilled water for 3 hours at $70-80^{\circ} \mathrm{C}$. This primary decoction was centrifuged at $3000 \mathrm{rpm}$ for 10 minutes. After removing the sediment, the decoction continued to be boiled down at $50-60^{\circ} \mathrm{C}$ until the decoction's concentration was $1 \mathrm{~g}$ : $1 \mathrm{~mL}$. This final decoction's concentration was $100 \%$, it had to be diluted into many different concentrations to investigate in vitro and in vivo antioxidant capacity assay.

Reducing power assay. Based on the ability of reducing potassium hexacyanoferrate (III) to potassium hexacyanoferrate (II) of the antioxidants, potassium hexacyanoferrate (II) reacts with ferric chloride to form a colored complex. It was measured at $700 \mathrm{~nm}$. The higher optical density value is, the greater antioxidant capacity is. The protocol was followed by the report of Jayanthi and Lalitha [3].

DPPH free radical scavenging assay. DPPH (1,1-diphenyl-2-picrylhydrazyl) is characterized as a stable free radical which shows maximum absorbance at $517 \mathrm{~nm}$. The 
lower optical density value is, the greater antioxidant capacity is. The antioxidant activity of decoction was measured by scavenging of free radicals by following the standard protocol (Brand - Williams et al., 1995) [4].

In vitro Lipid peroxidation inhibition capacity assay. Mus musculus var. albino (male; $6-8$ weeks; $20-30$ g body weight) were purchased from Pasteur Institute (167 Pasteur Street, District 3, Ho Chi Minh City). The mice were used in the experiments after an acclimatization period of seven days in the laboratory environment with a 12-hour light/ dark cycle and temperature of $28^{\circ} \mathrm{C}$. They were provided with food and water adequately. Cyclophosphamide is the main ingredient in endoxan (equivalent to $50 \mathrm{mg}$, Bartex ${ }^{\mathbb{R}}$ ) dissolved in distilled water to inject into the mice with the dose of $150 \mathrm{mg} / \mathrm{kg}$ body weight.

Cervical dislocation technique was used to kill nine mice. Then those mice were given a surgery and their livers were collected one day after cyclophosphamide injection. The liver was washed in cold salt water and weighed the liver. The liver was ground in phosphate buffer solution $\mathrm{pH}=7.4$ in a ratio of $1: 10$ at $0-4^{\circ} \mathrm{C}$, centrifuging $4000 \mathrm{rpm}$ at $4^{\circ} \mathrm{C}$ for 15 minutes, removing the sediment. $0.1 \mathrm{~mL}$ of various concentrations were mixed with $0.5 \mathrm{~mL}$ of the tissue homogenate and 1.4 $\mathrm{mL}$ of phosphate buffer and incubated the mixture at $37^{\circ} \mathrm{C}$ for 15 minutes. After that, 1 $\mathrm{mL}$ of trichloroacetic acid $(10 \% \mathrm{w} / \mathrm{v})$ was added and then centrifuged $10000 \mathrm{rpm}$ at $4^{\circ} \mathrm{C}$ for 10 minutes. $1 \mathrm{~mL}$ of thiobarbituric acid $(0,8 \% \mathrm{w} / \mathrm{v})$ was added into $2 \mathrm{~mL}$ of clear solution. This mixture was incubated for 15 minutes at a temperature of $90-100^{\circ} \mathrm{C}$. After cooling, this solution was measured at 532 $\mathrm{nm}$. The lipid peroxidation inhibition capacity (LPIC) of the decoction was calculated using the formula: LPIC $(\%)=\left[\left(\mathrm{A}_{\text {control }}-\mathrm{A}_{\text {sample }}\right) /\right.$ $\left.\mathrm{A}_{\text {control }}\right] \times 100$ ( $\mathrm{A}_{\text {control }}$ : the absorbance value of the control; $\mathrm{A}_{\text {sample: }}$ the absorbance value of the sample $[5,6]$. From lipid peroxidation inhibition capacity, correlation equation was built and the $\mathrm{IC}_{50}$ value was calculated.

In vivo Lipid peroxidation inhibition capacity assay.
Each experiment, one-day and sevenday, was arranged as follows. The mice were devided into 3 groups: a negative control, an experiment and a positive control. Each group had 3 mice. The three groups of mice were injected cyclophosphamide (CY). In the negative control, the mice weren't given the decoction. In the experimental group, the mice drank the flower decoction while in the positive control the mice drank d-Alpha tocopherol. After drinking the decoction in one day and seven days, the mice were killed by cervical dislocation technique. The liver was washed with cold salt water and weighted. The liver was ground in phosphate buffer solution $\mathrm{pH}=7.4$ in a ratio of $1: 10$ at $0-4^{\circ} \mathrm{C}$, centrifuged $4000 \mathrm{rpm}$ at $4^{\circ} \mathrm{C}$ for 15 minutes, removed the sediment. $2 \mathrm{~mL}$ tissue homogenate was mixed $1.4 \mathrm{~mL}$ phosphate buffer and incubated at $37^{\circ} \mathrm{C}$ for 60 minutes. After that, 1 $\mathrm{mL}$ of trichloroacetic acid $(10 \% \mathrm{w} / \mathrm{v})$ was added and then centrifuged $10000 \mathrm{rpm}$ at $4^{\circ} \mathrm{C}$ for 10 minutes. $1 \mathrm{~mL}$ of thiobarbituric acid $(0,8 \% \mathrm{w} / \mathrm{v})$ was added into $2 \mathrm{~mL}$ of solution. This mixture was incubated for 15 minutes at a temperature of $90-100^{\circ} \mathrm{C}$. After cooling, this solution was measured at $532 \mathrm{~nm}$. The content of malonyl dialdehyde (nmol/mL) was calculated using the formula: $\mathrm{C}_{\mathrm{MDA}}$ $(\mathrm{nmol} / \mathrm{mL})=\left(\mathrm{OD}_{\text {test }}-0.0029\right) / 0.0637[5,6]$. Based on the malonyl dialdehyde content ( $\mathrm{nmol} / \mathrm{mL}$ homogenate), the malonyl dialdehyde content (nmol/g protein) was calculated. Malonyl dialdehyde is a product of lipid peroxidation. The lower the malonyl dialdehyde content, the greater the capacity of the test sample to inhibit lipid peroxidation was (Janero \& Burghardt, 1988 \& Huong Nguyen Thi Thu \& Hang Nguyen Thi Ngoc, 2010) $[5,6]$.

Statical analysis. The data of the study were treated in the statistical SPSS, version 16. The values were presented as means \pm S.D. The correlation equation was determined by the equation with $\mathrm{p}<0.05$.

\section{Results.}

Results of in vitro antioxidant of the $\mathrm{Hi}$ biscus flower decoction. In this study, we have revealed that the decoction of Hibiscus rosa-sinensis flower exhibits in vitro antioxi- 
dant activity through reducing power assay and DPPH free radical scavenging assay. Based on the reducing capacity on ferreous ion, according to increasing concentration, the optical density value of the samples increases gradually ( $\mathrm{p}<0.05)$ (Fig. 1).

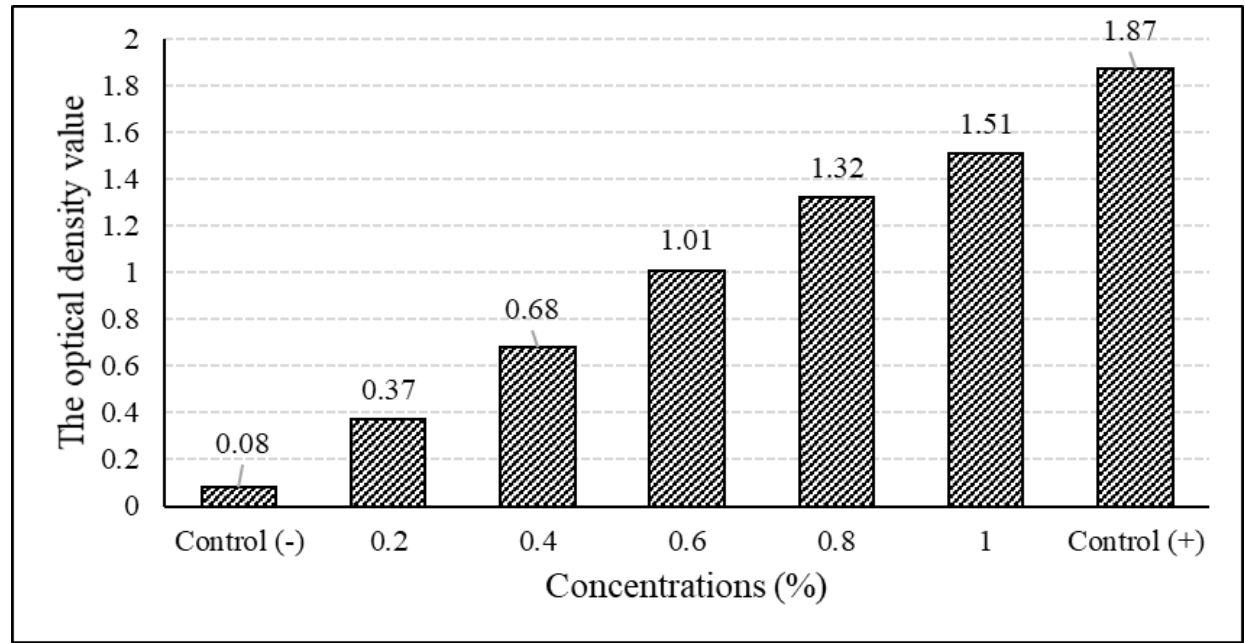

Fig. 1. The optical density value of Hibiscus flower decoction Control (-): the distilled water; Control (+): ascorbic acid $(28.16 \mu \mathrm{g} / \mathrm{mL})$

The radical scavenging activities of different concentrations of the decoction is showed in figure 2 . These results showed a strong DPPH free radical scavenging activity $(87.42 \pm 0.56 \%$ at $0.3 \%$ concentration) with $\mathrm{IC}_{50}$ of $0.13 \pm 0.01 \%$.

Result of lipid peroxidation inhibition capacity assay. When incubating the liver in the different concentrations of the decoction, the percentage of lipid peroxidation inhibition in- creased gradually ( $\mathrm{p} \leq 0.05)$ (Fig. 3 ). The correlation equation was $\mathrm{y}=26.023 \ln (\mathrm{x})+36.110$ $(\mathrm{R}=0.80)$. The $\mathrm{IC}_{50}$ value of decoction was $1.71 \pm 0.49 \%$ in the laboratory condition.

After one day and seven days of drinking decoction at a concentration of $1.71 \%$, the mouse liver was separated and the malonyl dialdehyde (MDA) content which is the product of lipid peroxidation was measured. These results are shown in figure 4.

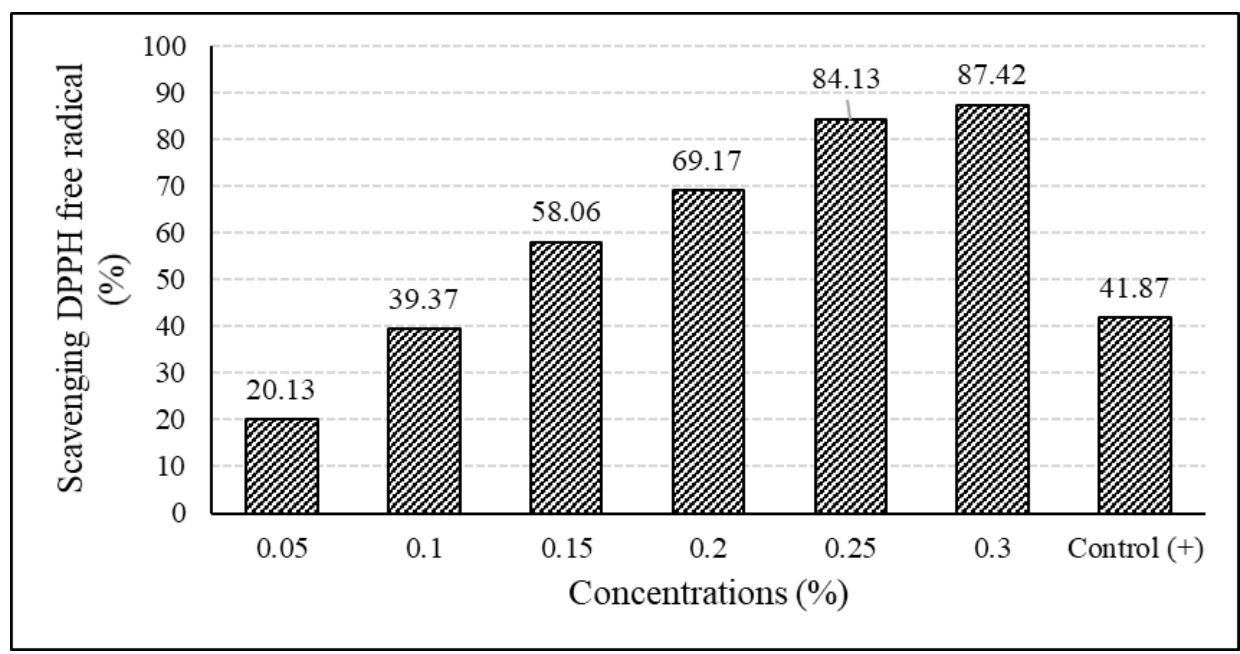

Fig. 2. The percentage of DPPH free radical scavenging of Hibiscus flower decoction $($ Control $(+)$ : ascorbic acid $(28.16 \mu \mathrm{g} / \mathrm{mL}))$ 


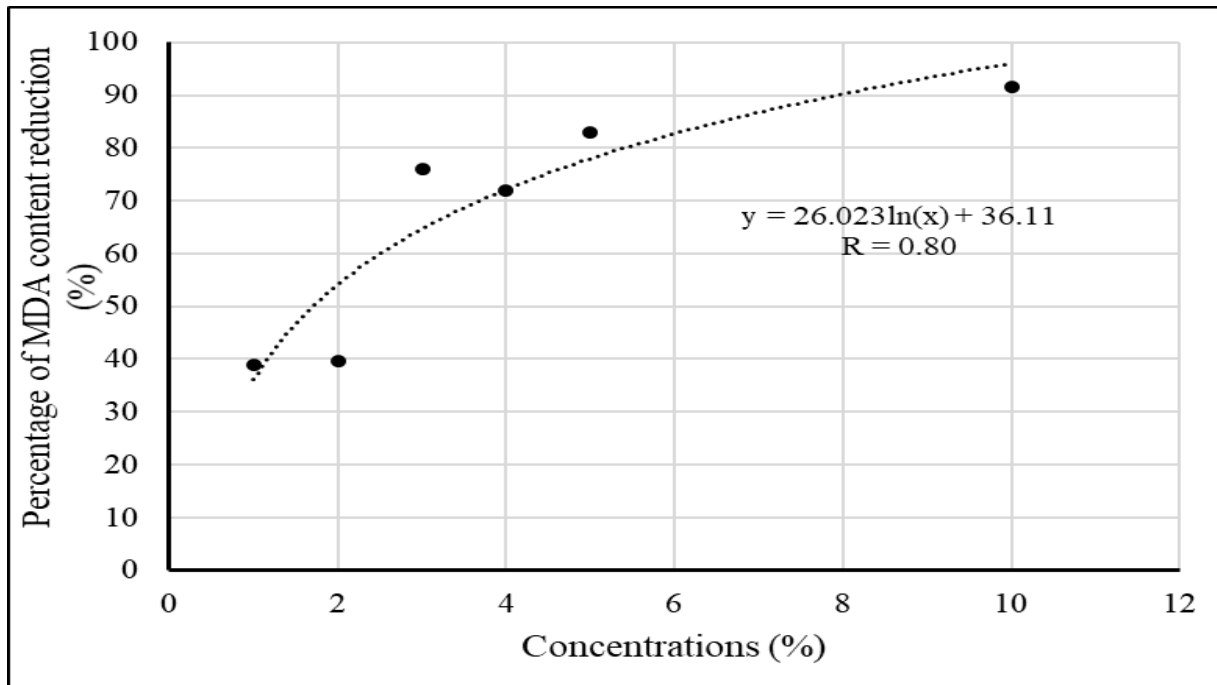

Fig. 3. The percentage of lipid peroxidation inhibition in vitro assay

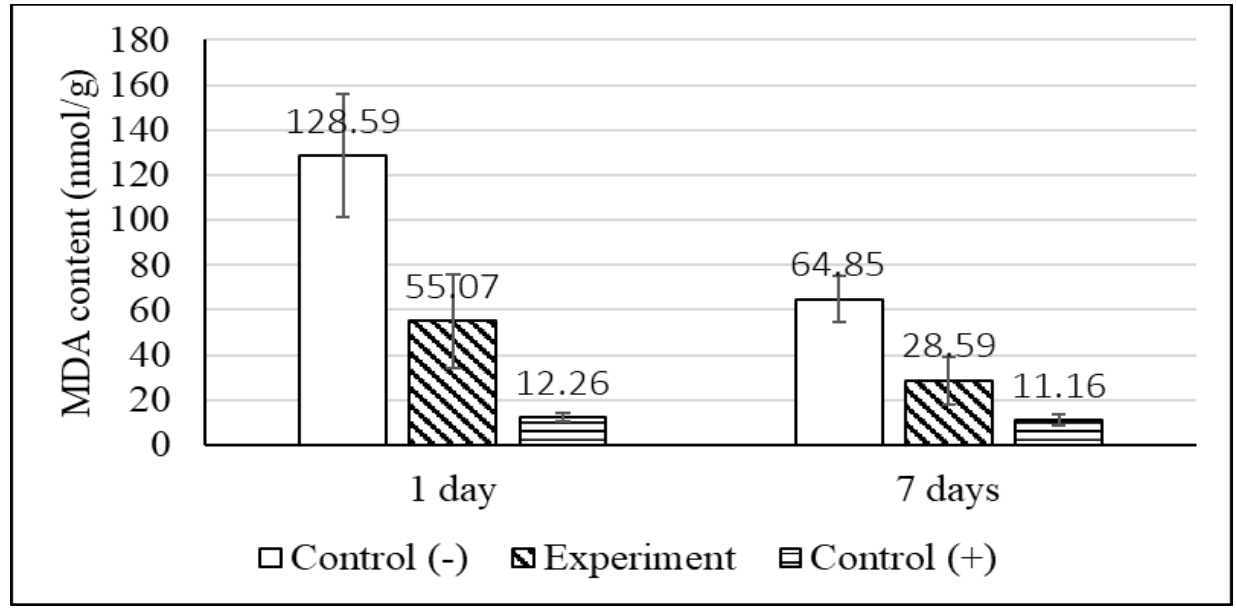

Fig. 4. The MDA content (nmol/g) in liver in vivo assay

After one day, when the mice were administered the decoction at $1.71 \%$ concentration, the MDA content decreased 2.33 times fewer than the negative control in the same experimental conditions. After seven days of drinking the decoction, the measured MDA content decreased by a factor of 2.27 compared to the negative control under the same experimental conditions. It showed that at this concentration, the decoction of Hibiscus flower had the ability to reduce the MDA content, inhibit the lipid peroxidation in the mice livers. Comparing the results of the oneday and seven-day trials, in both the negative control and the experimental group, the MDA level after 7 days decreased by a factor of 2 compared to that of one day, specifically in the negative control, the MDA content after seven days decreased by a factor of 1.98 compared to that of 1 day. When it comes to the experimental group, the MDA level after seven days dropped by a factor of 1.93 compared to that of one day.

\section{Discussion.}

According to Yin et al. (2013), $10 \mathrm{mg} / \mathrm{mL}$ ethanol and aqueous Hibiscus flower extract exhibited the percentage of DPPH inhibition was $83.08 \pm 0.1$ and $97.35 \pm$ 0.6 respectively. Moreover, they isolated some substances, the antioxidants, such as phenolics, tannins, flavonoids, anthocyanins the content of which in the aqueous extract was higher than in the ethanol extract [7]. Similarly, in the study of Wong et al. (2010), the methanol extract $(1 \mathrm{~g} / 50 \mathrm{~mL})$ exhibited ferric reducing power $(4.0 \pm 0.3)$, total phenolics content (735 $\pm 46 \mathrm{mg} / 100 \mathrm{~g})$, total anthocyanins content $(284 \pm 17 \mathrm{mg} / 100 \mathrm{~g})$ 
and ascorbic acid equivalent antioxidant capacity $(640 \pm 56 \mathrm{mg} \mathrm{AA} / 100 \mathrm{~g})$. The findings also support our result on the in vitro antioxidant activity of Hibiscus decoction [8].

Despite the difference of flower collecing location, the antioxidant activity of Hibis- cus rosa-sinensis flower decoction is similar to Chi Nguyen Minh et al. research (2016) through the percentage of DPPH scavenging activity and the $\mathrm{IC}_{50}$ value (Table) [2].

The \%DPPH scavenging activity comparision between two research

\begin{tabular}{|c|c|c|}
\hline Concentrations (\%) & This study results & Chi Nguyen Minh et al.' (2016) \\
\hline & \%DPPH scavenging activity & \%DPPH scavenging activity \\
\hline 0.1 & $39.37 \pm 2.07$ & $44.888 \pm 6.82$ \\
\hline 0.2 & $69.17 \pm 2.87$ & $72.470 \pm 7.00$ \\
\hline 0.4 & $87.71 \pm 0.44$ & $90.520 \pm 4.86$ \\
\hline 0.6 & $88.83 \pm 0.40$ & $91.812 \pm 2.23$ \\
\hline 0.8 & $87.89 \pm 0.72$ & $89.558 \pm 2.12$ \\
\hline 1 & $87.73 \pm 0.99$ & $87.535 \pm 3.28$ \\
\hline IC $_{\mathbf{5 0}}$ & $\mathbf{0 . 1 3} \pm \mathbf{0 . 0 1 \%}$ & $\mathbf{0 . 1 1 9} \pm \mathbf{0 . 0 2 \%}$ \\
\hline
\end{tabular}

Thus, the Hibiscus decoction exhibited the in vitro antioxidant activity through the reducing power assay and DPPH free radical scavenging assay.

Moreover, the antioxidant activity of the flower decoction was examined through the lipid peroxidation assay. In fact, the plasma membrane under attack of free radical will be lipid peroxidation and create malonyl dialdehyde. If the MDA level decline, the process of lipid peroxidation will decrease so the MDA assay reflects the antioxidant activity of the decoction. After the livers were incubated in the decoction at different concentrations, the MDA content declined steadily. The level of MDA was measured spectrophotometrically at $532 \mathrm{~nm}$. Due to the optical density value, the ability to inhibit the lipid peroxidation of the decoction of Hibiscus rosa-sinensis flower was assessed. The in vitro and in vivo lipid peroxidation results were similar. In the in vitro experiment, the percentage of lipid peroxidation inhibition was $50 \%$ at $1.71 \%$ concentration of the decoction. When the mice were injected with the decoction at a concentration of $1.71 \%$, according to the results of one-day and seven-day tests, the level of MDA in the experimental group decreased 2fold compared to the negative control.

The MDA content in the seven-day experiment decreased by a factor of roughly 1.9 compared to that of the one-day experiment. This result is coherent with the research of Lahouel (2004) [9]. Accordingly, the scien- tists examined the MDA content in the model of mice injected with cyclophosphamide and found that the MDA content in drinking water after - decreased by 1.7 times compared to the one-day test. This can be explained by the reduced glutathione content over time for seven days. Indeed, glutathione is the coactivator of the enzyme glutathione peroxidase, which decomposes $\mathrm{H}_{2} \mathrm{O}_{2}$ in mammalian cells [10]. However, the MDA level of the positive control in both one-day and sevenday experiments were not different (12.26 \pm $1.85 \mathrm{nmol} / \mathrm{g}$ protein and $11.16 \pm 2.62 \mathrm{nmol} / \mathrm{g}$ protein).

Conclusion. This finding indicated that the Hibiscus rosa-sinensis flower decoction exihibited the antioxidant activity through reducing power assay, DPPH free radical scavenging assay and lipid peroxidation assay. The decoction has the ability to reduce the level of malonyl dialdehyde by about 2 times compared to the negative control.

\section{Financial support}

Ho Chi Minh City University of Education has provided the financial support for this study.

\section{Conflict of interests}

The authors have no conflict of interest to declare.

\section{References}

1. Hoofnagle JH. LiverTox: Clinical and Research Information on DrugInduced Liver Inju- 
ry [Internet]. Bethesda (MD): National Institute of Diabetes and Digestive and Kidney Diseases; 2012; Cyclophosphamide. [Updated 2017 Nov 5]. Available from: https: //www.ncbi.nlm.nih.gov/books/NBK548059/

2. Chi Nguyen Minh, Giang Nguyen Thi Le, Lieu Pham Thi, Phuoc Truong Dinh, Thuong Tran Thi. [Study on the antioxidant activity and hypoglycemia of Hibiscus rosa-sinensis L. in Streptozotocin-Induced Diabetic Model]. Scientific research student conference in Ho Chi Minh City university of Education 2015 - 2016, 17-27. Retrieved from http://hcmup.edu.vn/index.php?option=com_conte $\mathrm{nt} \&$ view=article $\& \mathrm{id}=23361 \% 3 \mathrm{Ak}-\mathrm{yu}$-hi-ngh-svnckh-nm-hc-2015. Vietnamese.

3. Jayanthi P, Lalitha P. Reducing power of the solvent extracts of Eichhornia crassipes (Mart.) Solms. International Journal of Pharmacy and Pharmaceutical Sciences. 2011;3(3):126-128.

4. Brand-Williams W, Cuvelier ME, Berset C. Use of free radical method to evaluate antioxidant activity. Lebensmittel-Wissenschaft \& Technologie. $\quad 1995 ; 28: 25-30 . \quad$ DOI: https://doi.org/10.1016/S0023-6438(95)80008-5

5. Janero DR, Burghardt B. Analysis of cardiac membrane phospholipid peroxidation kinetics as malondialdehyde: Nonspecificity of thiobarbituric acid-reactivity. Lipids. 1988;23(5):452-458.

DOI: https://doi.org/10.1007/BF02535519

6. Huong Nguyen Thi Thu, Hang Nguyen Thi Ngoc. Study on Antioxidant Activity and Hepatoprotective Effect of Crude Polysaccharide Extracted from Ganoderma lucidum. Ho Chi Minh City Journal of Medicine. 2010;14(2):129134.

7. Yin WM, Li OC, Rosma A, et al. Antioxidant and antibacterial activities of hibiscus (Hibiscus rosa-sinensis L.) and Cassia (Senna bicapsularis L.) flower extracts. Journal of King Saud University - Science. 2013;25(4):275-282. DOI: https://doi.org/10.1016/j.jksus.2012.12.003

8. Wong SK, Lim Y Y, Chan EWC. Evaluation of Antioxidant, Anti-tyrosinase and Antibacterial Activities of Selected Hibiscus Species. Ethnobotanical Leaflets. 2010;14:781-96.

9. Lahouel M, Boulkour S, Segueni N, et al. The flavonoids effect against vinblastine, cyclophosphamide and paracetamol toxicity by inhibition of lipid-peroxydation and increasing liver glutathione concentration. Pathologie Biologie. 2004;52(6):314-322. DOI: https://doi.org/10.1016/j.patbio.2004.01.001

10. Ha Lai Thi Ngoc, Thu Vu Thi. Oxidative Stress and Natural Antioxidants. Viet Nam Journal of Agricultural Sciences. 2009;7(5):667677.

Received 3 March 2021

Revised 22 April 2021

Accepted 4 May 2021

\section{Information about the authors}

Hang Nguyen Thi, MSc, Laboratory Manager of the Genetics and Evolution, Biology Department, Ho Chi Minh City University of Education, Ho Chi Minh City, Vietnam, E-mail: hangnt@hcmue.edu.vn. ORCID: https://orcid.org/0000-0002-3334-3291.

Tai Phung Anh, Student at the Laboratory Genetics and Evolution, Biology Department, Ho Chi Minh City University of Education, Ho Chi Minh City, Vietnam, E-mail: 4301301048@student.hcmue.edu.vn, ORCID: https://orcid.org/0000-0002-6254-1537.

Hien Nguyen Thanh, Student at the Laboratory Genetics and Evolution, Biology Department, Ho Chi Minh City University of Education, Ho Chi Minh City, Vietnam, E-mail: 4301301014@student.hcmue.edu.vn, ORCID: https://orcid.org/0000-0003-2695-8922.

Duy Doan Ngoc Anh, Student at the Laboratory Genetics and Evolution, Biology Department, Ho Chi Minh city University of Education, Ho Chi Minh City, Vietnam, E-mail: 4301301010@student.hcmue.edu.vn, ORCID: https://orcid.org/0000-0002-3809-0115.

Linh Nguyen Anh, Student at the Laboratory Genetics and Evolution, Biology Department, Ho Chi Minh City University of Education, Ho Chi Minh City, Vietnam, E-mail: 4301301025@student.hcmue.edu.vn, ORCID: https://orcid.org/0000-0002-7972-2254.

Huyen Nguyen Thi Thuong, PhD, Department of Animals Physiology, Biology Faculty, Ho Chi Minh City University of Education, Ho Chi Minh City, Vietnam, E-mail: huyenntth@hcmue.edu.vn, ORCID: https://orcid.org/0000-0003-2855-2942. 